Article

\title{
Preparation of Renewable Bio-Polyols from Two Species of Colliguaja for Rigid Polyurethane Foams
}

\author{
Diana Abril-Milán ${ }^{1}\left(\mathbb{D}\right.$, Oscar Valdés ${ }^{2, *} \mathbb{1}$, Yaneris Mirabal-Gallardo ${ }^{3}$, \\ Alexander F. de la Torre ${ }^{4} \mathbb{D}$, Carlos Bustamante ${ }^{5}$ and Jorge Contreras ${ }^{5}$ \\ 1 Departamento de Biología y Química, Facultad de Ciencias Básicas, Universidad Católica del Maule, \\ 3460000 Talca, Chile; dabril@ucm.cl \\ 2 Vicerrectoría de Investigación y Postgrado, Universidad Católica del Maule, 3460000 Talca, Chile \\ 3 Instituto de Ciencias Químicas Aplicadas, Facultad de Ingeniería Civil, Universidad Autónoma de Chile, \\ 3460000 Sede Talca, Chile; yaneris.mirabal@uautonoma.cl \\ 4 Departamento de Química Orgánica, Facultad de Ciencias Químicas, Universidad de Concepción, \\ Casilla 160-C, 4030000 Concepción, Chile; afernandezd@udec.cl \\ 5 Facultad de Ciencias Agrarias y Forestales, Universidad Católica del Maule, 3460000 Talca, Chile; \\ cbustamantevaldes@gmail.com (C.B.); jcontrer@ucm.cl (J.C.) \\ * Correspondence: ovaldes@ucm.cl; Tel.: +56(71)-2203304
}

Received: 27 September 2018; Accepted: 8 November 2018; Published: 11 November 2018

\begin{abstract}
In this study, we investigated the potential of two non-edible oil extracts from seeds of Colliguaja integerrima (CIO) and Colliguaja salicifolia (CSO) to use as a renewable source for polyols and, eventually, polyurethane foams or biodiesel. For this purpose, two novel polyols from the aforementioned oils were obtained in a one-single step reaction using a mixture of hydrogen peroxide and acetic acid. The polyol derivatives obtained from the two studied oils were characterized by spectral (FTIR, ${ }^{1} \mathrm{H}$ NMR, and ${ }^{13} \mathrm{C}$ NMR), physicochemical (e.g., chromatographic analysis, acid value, oxidizability values, iodine value, peroxide value, saponification number, kinematic viscosity, density, theorical molecular weight, hydroxyl number, and hydroxyl functionality) and thermal (TGA) analyses according to standard methods. Physicochemical results revealed that all parameters, with the exception of the iodine value, were higher for bio-polyols (CSP and CIP) compared to the starting oils. The NMR, TGA, and FTIR analyses demonstrated the formation of polyols. Finally, the $\mathrm{OH}$ functionality values for CIP and CSP were 4.50 and 5.00, respectively. This result indicated the possible used of CIP and CSP as a raw material for the preparation of polyurethane rigid foams.
\end{abstract}

Keywords: Colliguaja integerrima; Colliguaja salicifolia; vegetable oil; bio-polyol; renewable resources

\section{Introduction}

The high demand for products from petrochemical origin and their negative effects on the environment, parallel to the growing scarcity of these non-renewable resources, are factors that have encouraged the chemical industry to look for new sources of renewable resources as raw materials. These raw materials have contributed in a very positive way to the sustainable development of the plastics industry, due to the great synthetic potential of nature and different principles of green chemistry [1,2]. Vegetable oils are one of the most considered alternatives due to abundance, low toxicity, biodegradability, inherent fluidity, and low cost [3-5]. Several vegetable oil molecules must be chemically transformed to form polyols, and these bio-polyols are used for the obtention of polyurethanes [6], polyesters [7], and epoxy [8], among others.

The synthesis of bio-polyols from fatty acids and vegetable oils has been the focus of many studies. It is important to note that vegetable oils, with the exception of castor and lesquerella oils, 
do not contain hydroxyl groups. For that reason, it is necessary to chemically modify the vegetable oils to introduce hydroxyl groups into their structures to produce polyols. There are five different pathways for vegetable oil-based bio-polyol production: (1) epoxidation and oxirane ring-opening [9]; (2) hydroformylation and hydrogenation [10,11]; (3) ozonolysis [12]; (4) thiol-ene coupling [13]; and (5) transesterification/amidation [14]. The first method is the most widely used. Researchers regularly use this method in one or two steps. "The one-step reaction consists of the in situ epoxidation followed by hydroxylation using acetic and sulfuric acids and hydrogen peroxide. The two-step reaction deals with the triglyceride epoxidation followed by the ring-opening of oxirane, based on the use of difunctional molecules such as alcohols or amines" $[15,16]$. This multi-step synthesis would unquestionably increase the cost of bio-polyol production.

It is important to mention that various vegetable oils, including palm, soybean, sunflower, rapeseed, and canola oils, are used with slight modifications to produce polyols [17-22]. The great inconvenience with some of these oils are their use in food, which bring, as a consequence, a global imbalance to the food supply and demand in the industrial market [23].

Therefore, this study concentrates in the obtention of new bio-polyols from two non-edible oil extracts from seeds of Colliguaja integerrima and Colliguaja salicifolia by a single one-step reaction using a mixture of hydrogen peroxide and acetic acid. In addition, we characterized the prepared oils and polyols using various physicochemical, spectroscopic, and thermoanalytical methods.

C. integerrima and C. salicifolia are two varieties of the Euphorbiaceae family. The Euphorbiaceae family, with around 300 genera and over 7000 species, is one of the largest and most diverse families of flowering plants [24]. Both species grow wild in South America, specifically in the phytogeographical provinces of Patagonia and Monte in Argentina and Chile [25-27]. The oil extracted from these two species are known for the diuretic activity of their aqueous extract [28]. To our knowledge, no studies have been previously reported about the production of polyols from C. integerrima and C. salicifolia using a cheap and environmentally benign method.

\section{Experimental Procedures}

\subsection{Chemicals and Reagents}

Diethyl ether $\left(\mathrm{C}_{4} \mathrm{H}_{10} \mathrm{O}\right)$, $n$-hexane, glacial acetic acid $(\mathrm{AcOH})$, hydrogen peroxide $\left(\mathrm{H}_{2} \mathrm{O}_{2}\right)$, toluene $\left(\mathrm{C}_{7} \mathrm{H}_{9}\right)$, sulfuric acid $\left(\mathrm{H}_{2} \mathrm{SO}_{4}\right)$, sodium sulfate $\left(\mathrm{Na}_{2} \mathrm{SO}_{4}\right)$, sodium carbonate $\left(\mathrm{Na}_{2} \mathrm{CO}_{4}\right)$, sodium thiosulfate pentahydrate, and potassium hydroxide $(\mathrm{KOH})$ were supplied by Arquimed (Santiago, Chile). Iodine monochloride solution (Wijs reagent), starch solution, tetrahydrofuran (THF), and phenolphthalein reagent were purchased from Sigma-Aldrich (St. Louis, MO, USA). All used reagents were of analytical grade, with the exception of $n$-hexane and tetrahydrofuran (HPLC purity grade). For GC-MS analysis, Supelco ${ }^{\circledR} 37$ component fatty acid methyl ester (FAME) mix in dichloromethane (varied concentrations) was purchased from Sigma-Aldrich.

\subsection{C. integerrima and C. salicifolia Seeds}

The seeds of C. salicifolia and C. integerrima were collected in Cayurranquil, a geographic area in the Cauquenes Province $(725468,6017270)$ and the Pehuenche International Pathway, Los Cóndores, at the foothills of Talca $(348271,6026739)$ Chile, respectively.

\subsection{Vegetable Oil Extraction}

Oil extraction was performed according to the AOAC method Am2-93 [29]. About $250 \mathrm{~g}$ of C. integerrima seeds were extracted using $n$-hexane $(150 \mathrm{~mL})$ as an extraction solvent in a Soxhlet apparatus. After $8 \mathrm{~h}$, the $n$-hexane was removed by distillation under reduced pressure at $40^{\circ} \mathrm{C}$. The obtained $\mathrm{C}$. integerrima orange oil (CIO) was stored at $4{ }^{\circ} \mathrm{C}$ under inert atmosphere until further investigation. The extraction was performed in triplicate for each harvested sample, obtaining a $26 \%$ 
yield. The same procedure was used for the C. salicifolia but, in this case, the oil (CSO) obtained had a yellow coloration with $23 \%$ of yield.

\subsection{Synthesis of C. integerrima and C. salicifolia Polyol}

The synthesis of the polyols was carried out following the methodology described by Monteavaro et al. [30] with slight modifications. A solution of $5 \mathrm{~g}(5.6 \mathrm{mmol})$ of $C$. integerrima oil and $9.30 \mathrm{~mL}$ $(0.162 \mathrm{~mol})$ of glacial acetic acid in $20 \mathrm{~mL}$ of toluene, with some drops of sulfuric acid, were placed into a 3-necked flask equipped with a mechanical stirrer, reflux condenser, and isobaric funnel. The mixture was mechanically stirred at room temperature until complete homogenization. After that, a solution of $30 \% \mathrm{H}_{2} \mathrm{O}_{2}(5.30 \mathrm{~mL})$ was slowly added controlling the temperature. When the $\mathrm{H}_{2} \mathrm{O}_{2}$ addition was completed, the mixture was heated to $60^{\circ} \mathrm{C}$ for $12 \mathrm{~h}$. Then, the reaction mixture was cooled to room temperature and a $10 \%(\mathrm{w} / \mathrm{v})$ sodium bisulfide solution was added, and the mixture was stirred for $20 \mathrm{~min}$ to eliminate excess peroxide. After that, $50 \mathrm{~mL}$ of ethyl ether was added to the mixture, and the organic phase was washed several times with $10 \%(\mathrm{w} / \mathrm{v})$ sodium carbonate solution to neutral $\mathrm{pH}$. Finally, the organic phase was dried over sodium sulfate, and concentrated under vacuum to eliminate the ethyl ether to obtain the $C$. integerrima polyol (CIP). The same procedure was used for the synthesis of C. salicifolia polyol (CSP).

\subsection{Characterization Methods Used for Oils and Polyols}

The C. integerrima and C. salicifolia oils and polyols were characterized determining the fatty acid composition, the oxidizability value (Cox), acid value (AV), iodine value (IV), saponification number (SN), kinematic viscosity, peroxide value (PV), density, hydroxyl number, thermogravimetric analysis (TGA), Fourier transform infrared (FTIR), and ${ }^{1} \mathrm{H}$ and ${ }^{13} \mathrm{C}$ NMR spectroscopy. It is important to note that the fatty acid composition, peroxide value, and the oxidizability value were performed only for the studied oils, and the rest of the characterization techniques were done for the C. integerrima and C. salicifolia oils and polyols.

The fatty acid profile was determined only for the C. integerrima and C. salicifolia oils as fatty acid methyl esters by gas chromatography-mass spectrometry. The methyl esters were prepared using the method described by Morrison and Smith [31]. The separation of the fatty acid esters was performed using QP 5000 Shimadzu (Kyoto, Japan) gas chromatographer with mass spectrometer and autosampler was used, as well as the 1.2 Class-5000. A fused-silica column, coated with the DB-5 stationary phase, was utilized $(30 \mathrm{~m} \times 0.2 \mathrm{~mm}$ inner diameter, dry film thickness of $0.25 \mu \mathrm{m}$, $\mathrm{J} \& \mathrm{~W}$ Scientific). The initial oven temperature was $60^{\circ} \mathrm{C}$, which was kept for $5 \mathrm{~min}$; a $2{ }^{\circ} \mathrm{C} \mathrm{min}^{-1}$ temperature increase was programed until it reached $220^{\circ} \mathrm{C}$; this temperature was kept for $30 \mathrm{~min}$. The injector temperature was $220^{\circ} \mathrm{C}$. Helium was used as a carrier gas with a $1.0 \mathrm{~mL} \mathrm{~min}{ }^{-1}$ flow. The injection volume was $1 \mu \mathrm{L}\left(1 \%\right.$ solution in $\left.\mathrm{CH}_{2} \mathrm{Cl}_{2}\right)$ with a 1:10 split ratio. Column pressure was $100 \mathrm{kPa}$. Mass detector conditions were the following: source temperature, $240{ }^{\circ} \mathrm{C}$; electron impact mode (EI), $70 \mathrm{eV}$; scan rate of $1 \mathrm{scan} \mathrm{s}^{-1}$; and acquisition range, 29-450 u. Components were identified by comparing retention times related to a linear standard made with Supelco ${ }^{\circledR} 37$ Component FAME Mix in dichloromethane (varied concentrations) of an alkane series (C9-C24) and their mass spectra to those from the Wiley 330000 database and the ones reviewed from the literature. In addition, with the percentage of unsaturated fatty acids, we calculated the oxidizability values (Cox) of $C$. integerrima and C. salicifolia oils, applying the formula proposed by Fatemi et al. [32]:

$$
\text { Cox }=\frac{[1(16: 1 \%+18: 1 \%+20.1 \%)+10.3(18: 2 \%+20: 2 \%)+21.6(18: 3 \%)]}{100}
$$

The acid value, iodine value, peroxide value, and saponification number of the obtained samples (C. integerrima and C. salicifolia oils and polyols) were determined according to the AOCS Official Method Cd 3d-63, AOAC Official Method 920.158 (Hanus method), AOAC Official Method 965.33 
and the AOAC Official Method 920.160, respectively [33,34]. The theorical molecular weights of both polyols were calculated using the formula proposed by Zlatanić et al. [35].

The structure of samples (C. integerrima and C. salicifolia oils and polyols) were analyzed by ${ }^{1} \mathrm{H}$ and ${ }^{13} \mathrm{C}$ NMR, and FTIR spectroscopy, combined with hydroxyl number measurement. ${ }^{1} \mathrm{H}$ and ${ }^{13} \mathrm{C}$ NMR spectra were conducted with a Varian Inova 300 (Varian, Inc., Palo Alto, CA, USA), 300 MHz, using $\mathrm{CDCl}_{3}$ as a solvent and tetramethylsilane as an internal reference. FTIR spectra were recorded using an Agilent Cary 360 FTIR in the range of 4000 to $650 \mathrm{~cm}^{-1}$ at a resolution of $4 \mathrm{~cm}^{-1}$ with 32 scans on ATR (Agilent Technologies, Palo Alto, CA, USA). Two milliliters of the C. integerrima and C. salicifolia oil and polyol samples were put directly on the equipment plate without any previous treatment. The hydroxyl number of the C. integerrima and C. salicifolia polyols was determined according to ASTM 4274-05 [36]. The viscosity of the C. integerrima and C. salicifolia oil and polyol samples were measured by Brookfield viscometer (LVDV-II, Brookfield Engineering Laboratories, Inc., Stoughton, Massachusetts) at $25 \pm 0.5^{\circ} \mathrm{C}$. The density of the C. integerrima and C. salicifolia oil and polyol samples were measured by means of a pycnometer at $25 \pm 0.5^{\circ} \mathrm{C}$. Finally, thermal stability of the oils and polyols were performed in a thermogravimetric analyzer NETZSCH TG 209F1 Iris (NETZSCH Company, Germany) with $10^{\circ} \mathrm{C} \mathrm{min}^{-1}$ constant heating rate. The heating was from $30{ }^{\circ} \mathrm{C}$ to $500{ }^{\circ} \mathrm{C}$ in inert atmosphere with a flow rate of $60 \mathrm{~mL} \mathrm{~min}^{-1}$.

\section{Results and Discussion}

\subsection{Physicochemical Characteristics of Vegetable Oils}

The chemical composition and characteristics of the precursor of polyols $(C$. integerrima and C. salicifolia oils) used in this study are shown in Table 1. In addition, we determined the acid value, cox value, iodine value, peroxide value, saponification number, kinematic viscosity, and density of these oils.

As can we see, the saturated fatty acids (SFAs) of the oils differ very little, because the percentage of palmitic acid, which is the main SFA, is similar in the two studied oils. On the other hand, the percentages of unsaturated fatty acids (UFAs), were $87.36 \mathrm{and} 88.23 \%$ for CIO and CSO, respectively. Specifically, the dominant constituents (over $80 \%$ ) of both studied oils are C18 fatty acids, in spite of there also being about $7 \%$ of $C 20$ fatty acids. The percentage value of linoleic acid (C 18:2) was observed in $31.11 \%$ and $20.40 \%$ for CIO and CSO, respectively. The main differences between CIO and CSO are derived from the percentage of linolenic acid (C 18:3), observed in 26.39 and 46.60, respectively. Figure 1 shows the chemical structures of linoleic and linolenic acids found in CIO and CSO. It is important to note that this difference in the distribution of the double bonds in the fatty acid chains is fundamental for knowing the possibilities of increasing $\mathrm{OH}$ groups in the polyols synthetized using these oils, and directly proportional to their potential as a future polyurethane foam.

a)

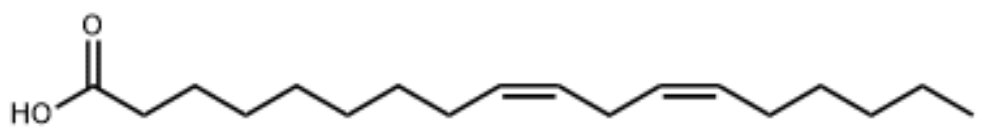

b)

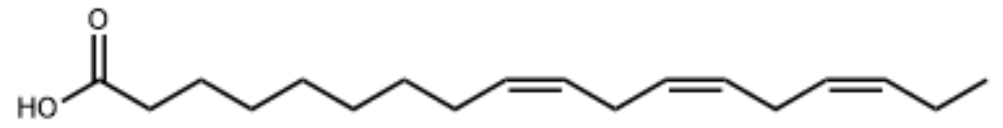

Figure 1. Chemical structures of linoleic (a) and linolenic (b) acids found in C. integerrima oil (CIO) and C. salicifolia oil (CSO).

Taking into account the abovementioned and using the measured composition (lipid profile), we measured the degree of unsaturation by the iodine value (IV), which is directly related to the Cox 
value for CIO and CSO. The results for CIO and CSO indicated values of IV (143.8 and $179.3 \mathrm{~g} \mathrm{I}_{2} / 100 \mathrm{~g}$, respectively) and Cox (9.35 and 12.46, respectively), providing it a particular resistance to oxidation. The saponification value (SN), which is a parameter related with the molecular mass of the fatty acids found in the oil, was also studied. The SN values for CIO and CSO were 196 and $194 \mathrm{mg} \mathrm{KOH} / \mathrm{g}$ oil, respectively, which are in the average SN range of $175-250 \mathrm{mg} / \mathrm{g}$ reported for common vegetable oils [37]. It should be noted that these values do not show significant differences, which means that the fatty acid composition of the studied oils are similar in molecular weight. It is known that acid value (AV) measures the number of carboxylic acid groups present in fat or oil; this value must not be too high, because it is a result of the hydrolysis of triglycerides. The highest acid value was found for $\mathrm{CSO}(0.25 \mathrm{mg} \mathrm{KOH} / \mathrm{g}$ oil), however, the AV for both studied oils was less than $1.0 \mathrm{mg} \mathrm{KOH} / \mathrm{g}$ oil (See Table 1), indicating that oils did not undergo hydrolytic processes. Additionally, the peroxide value (PV) of CIO and CSO were similar, and less than $20 \mathrm{meq} / \mathrm{kg}$, respectively, indicating that these oils were unoxidized and of high initial quality.

Finally, we also measured the kinematic viscosity and density for CIO and CSO. Generally, the kinematic viscosity is related to a measure of the internal friction or resistance of an oil to flow. According to Krisnangkura et al. [38], viscosity may be considered the interaction forces of molecules. The viscosity values shown in Table 1 were 58.6 and $48.8 \mathrm{~mm}^{2} / \mathrm{s}$ for CIO and CSO, respectively. The difference in these values is due to the degree of unsaturation presented in both studied oils, and is in concordance with the results reported by Rodrigues Jr et al. [39]. In this research, Rodrigues Jr reported that one double bond increased the viscosity, whereas two or three double bonds caused a decrease in the viscosity of the systems. On the other hand, density is an important physical characteristic of any substance, and is the weight of a unit volume of fluid [40]. In this case, the values reported in Table 1 are 0.884 and $0.896 \mathrm{~g} / \mathrm{cm}^{3}$ for CIO and CSO, respectively. It is important to know that all reported values shown in Table 1 (physical characteristics) of CIO and CSO had a drastic change in their numerical values when the oils became their respective polyols.

Table 1. Chemical composition and characteristics of C. integerrima oil (CIO) and C. salicifolia oil (CSO).

\begin{tabular}{|c|c|c|}
\hline \multirow{2}{*}{ Parameters } & \multicolumn{2}{|c|}{ Oils } \\
\hline & $\mathrm{CIO}$ & CSO \\
\hline \multicolumn{3}{|l|}{ Fatty acid (\%) } \\
\hline Myristic, $C_{14: 0}$ & 0.06 & 0.04 \\
\hline Palmitic, $\mathrm{C}_{16: 0}$ & 10.54 & 8.46 \\
\hline Palmitoleic, $\mathrm{C}_{16: 1}$ & 0.05 & 0.08 \\
\hline Margaric, $\mathrm{C}_{17: 0}$ & 0.00 & 0.00 \\
\hline Stearic, $\mathrm{C}_{18: 0}$ & 2.03 & 2.06 \\
\hline Oleic, $\mathrm{C}_{18: 1}$ & 23.50 & 15.08 \\
\hline Linoleic, $C_{18: 2}$ & 31.11 & 20.40 \\
\hline Gamma- linolenic, $C_{18: 3}$ & 0.48 & 0.00 \\
\hline Alpha-linolenic, $C_{18: 3}$ & 26.39 & 46.60 \\
\hline Gondoic, $\mathrm{C}_{20: 1}$ & 5.35 & 6.34 \\
\hline Eicosadienoic $C_{20: 2}$ & 0.48 & 0.73 \\
\hline Cox value & 9.35 & 12.24 \\
\hline $\mathrm{AV}$ (mg KOH/g oil) & 0.17 & 0.25 \\
\hline $\mathrm{IV}\left(\mathrm{g} \mathrm{I}_{2} / 100 \mathrm{~g}\right.$ oil $)$ & 143.8 & 179.3 \\
\hline $\mathrm{PV}$ (meq $\mathrm{O}_{2} / \mathrm{kg}$ oil) & 19 & 18 \\
\hline $\mathrm{SN}$ (mg KOH/g oil) & 196 & 194 \\
\hline Kinematic Viscosity $\left(\mathrm{mm}^{2} / \mathrm{s}\right)$ & 58.6 & 48.8 \\
\hline Density $\left(\mathrm{g} / \mathrm{cm}^{3}\right)$ & 0.884 & 0.896 \\
\hline
\end{tabular}

3.2. Synthesis and Characterization of C. integerrima and C. salicifolia Polyols Prepared by a One-Step Synthesis

The main goal of our research was to prepare polyols from CIO and CSO, respectively. C. integerrima and C. salicifolia polyols (CIP and CSP, respectively) were prepared by a one-step 
synthesis using the acetic acid $/ \mathrm{H}_{2} \mathrm{O}_{2}$ system. The results reveal a wide difference of physicochemical characteristics among both obtained polyols and their starting oils. The measures of $\mathrm{OH}$ functionality was given an idea of the characteristics of the polyol obtained. For example, if the reaction was complete we obtained a polyol with high $\mathrm{OH}$ functionality. On the contrary, if the reaction was partial we obtained a polyol with remaining epoxy groups. These two results will be depending on the reaction conditions. As previously mentioned, we obtained CIP and CSP with OH numbers of 225.0 and $240.8 \mathrm{mg} \mathrm{KOH} / \mathrm{g}$ (See Table 2), respectively. According to these values, it is evident that both hydroxylation reactions to obtain the CIP and CSP were complete, which are coherent with the NMR and FTIR results.

Table 2. Chemical composition and characteristics of C. integerrima polyol(CIP) and C. salicifolia polyol (CSP).

\begin{tabular}{lcc}
\hline \multirow{2}{*}{\multicolumn{1}{c}{ Parameters }} & \multicolumn{2}{c}{ Polyols } \\
\cline { 2 - 3 } & CIP & CSP \\
\hline $\mathrm{AV}(\mathrm{mg} \mathrm{KOH} / \mathrm{g})$ & 4.50 & 12.95 \\
$\mathrm{IV}\left(\mathrm{g} \mathrm{I}_{2} / 100 \mathrm{~g}\right)$ & 0.2 & 0.5 \\
$\mathrm{SN}(\mathrm{mg} \mathrm{KOH} / \mathrm{g})$ & 227 & 235 \\
Kinematic Viscosity $\left(\mathrm{mm}^{2} / \mathrm{s}\right)$ & 3637 & 5746 \\
Density $\left(\mathrm{g} / \mathrm{cm}^{3}\right)$ & 1.012 & 0.921 \\
Molar Mass $(\mathrm{g} / \mathrm{mol})$ & 1122.4 & 1166.1 \\
$\mathrm{OH}_{\text {numbers }}(\mathrm{mg} \mathrm{KOH} / \mathrm{g})$ & 225.0 & 240.8 \\
OH functionality & 4.50 & 5.00 \\
\hline
\end{tabular}

\subsection{1. ${ }^{1} \mathrm{H}$ and ${ }^{13} \mathrm{C}$ NMR Analysis}

The functional group present in the CIP and CSP, with their respective starting oils, was confirmed by ${ }^{1} \mathrm{H}$ NMR, ${ }^{13} \mathrm{C}$ NMR, and FTIR analyses, and the results are shown in Figures $2-4$, respectively. It is known that polyols are a complex blend of products. For that reason, the NMR spectra analysis was performed by zone, because each zone gives indications about the average structure of polyols.

Figure 2a,c shows the ${ }^{1} \mathrm{H}$ NMR spectra of CIP and CSP, respectively. The main difference between polyols and their corresponding oils (Figure $2 b, d$ ) in the ${ }^{1} \mathrm{H}$ NMR spectra were the appearance of new peaks in the zone between 3.27 and $3.83 \mathrm{ppm}$, which are assigned to the presence of methylene protons attached to the hydroxyl group $(-\mathrm{CH}-\mathrm{OH})$. In addition, the signal corresponding to the olefinic hydrogen $(-\mathrm{CH}=\mathrm{CH}-)$ that appeared in the zone between 5.32 and $5.44 \mathrm{ppm}$ disappeared, suggesting that polyol structures were practically without unsaturation. However, the signal corresponding to the methynic hydrogen of the glycerol moiety between 5.18 and $5.30 \mathrm{ppm}\left(\mathrm{ROOCH}_{2}\right)_{2} \mathrm{CH}(\mathrm{OOR})$ remained. Finally, the absence of signals in the zone between 2.8 and $3.2 \mathrm{ppm}$, relative to the epoxide groups $(-\mathrm{CH}(\mathrm{O}) \mathrm{CH}-)$, confirmed the occurrence of the hydroxylation reaction to obtain the CIP and CSP.

On the other hand, the ${ }^{13} \mathrm{C}$ NMR spectra of CIP and CSP with their respective starting oils offer similar information (See Figure 3). These spectra were characterized by the almost disappearance of the ethenic double bond signs of both starting oils, and the appearance of a new sign in 75.32 $\mathrm{ppm}$, which corresponds to - $\mathrm{CH}-\mathrm{OH}$ groups formed during the epoxy-opened ring. In agreement with the results obtained by the ${ }^{1} \mathrm{H}$ NMR spectra, the signals centered in $54.38 \mathrm{ppm}$, relative to the epoxide groups nonappearance, proved the formation of polyols. Furthermore, the signal found at 173-175 ppm, relative to the carbonyl ester, showed a peak present in both oils and polyols.

Finally, it is important to mention that, in both polyol spectra, appear signals corresponding to the residual toluene used in the synthesis process. The signals corresponding to the toluene structure were found at $\delta 21.4,125.2,128.3,129.2 \mathrm{ppm}$, and 2.35, 7.0-7.3 ppm for ${ }^{13} \mathrm{C}$ NMR and ${ }^{1} \mathrm{H}$ NMR, respectively. This evidence confirmed that the elimination of toluene was ineffective. 
a)

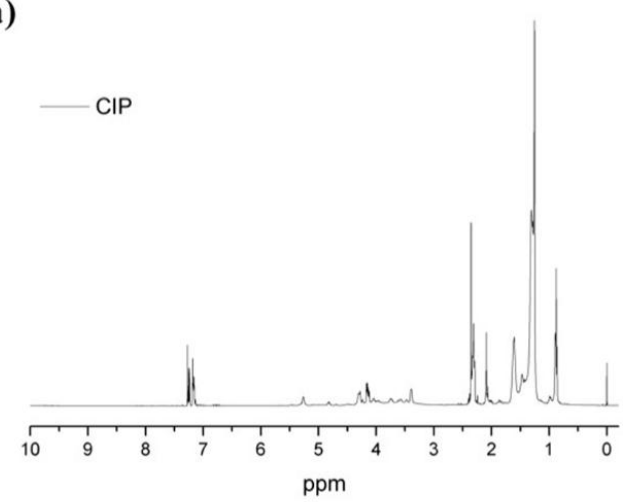

c)

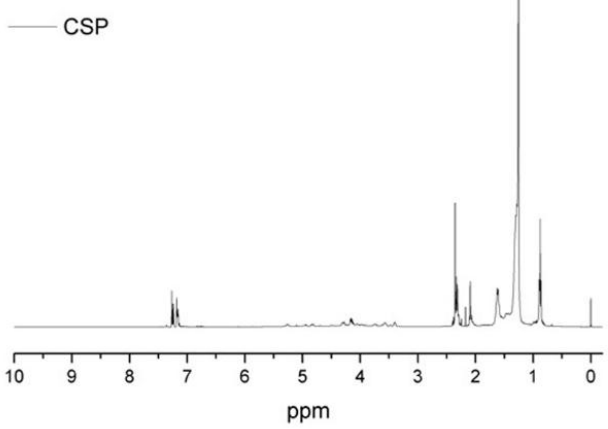

b)

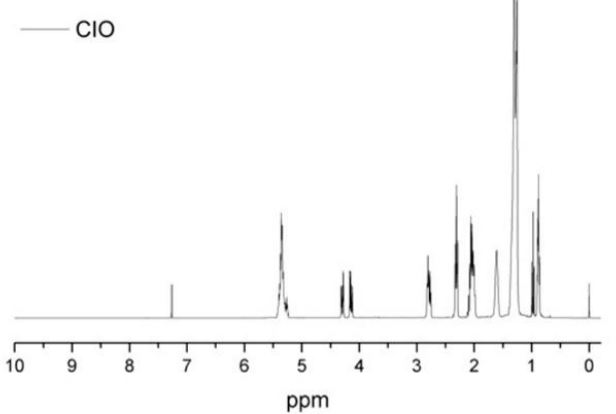

d)

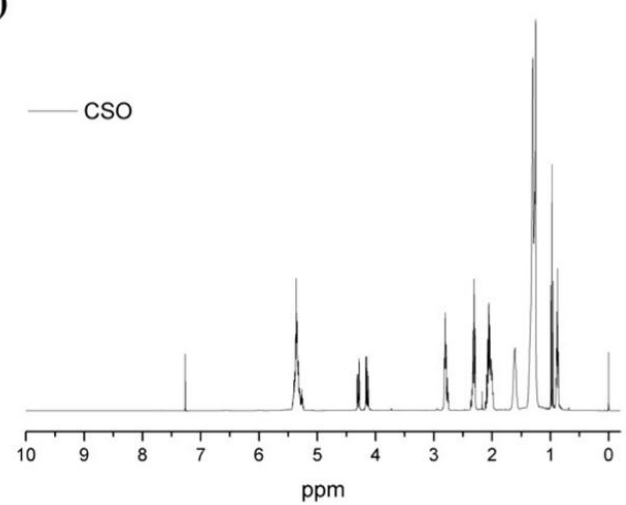

Figure 2. ${ }^{1} \mathrm{H}$ NMR spectra of CIP (a), CSP (c) whit their respective $\mathrm{CIO}(\mathbf{b})$ and $\mathrm{CSO}(\mathbf{d})$.

a)

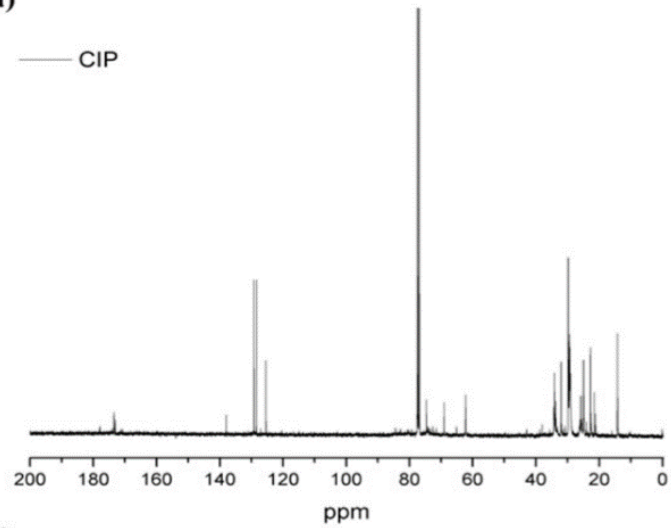

c)

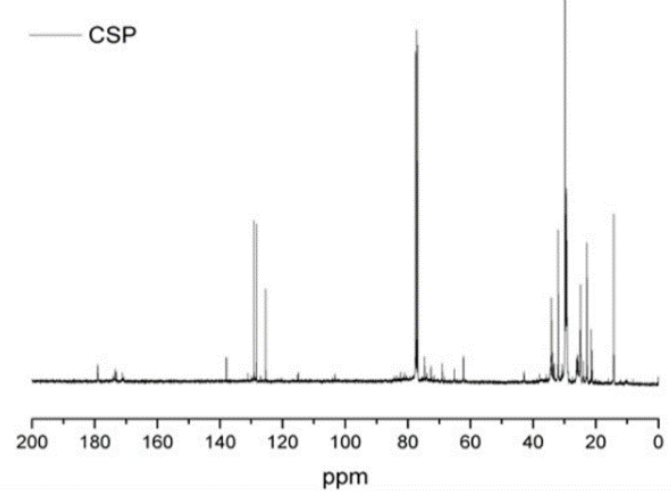

b)

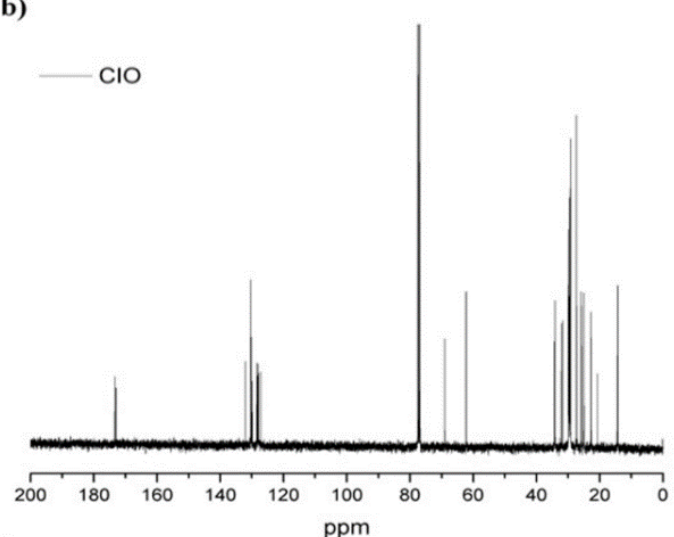

d)

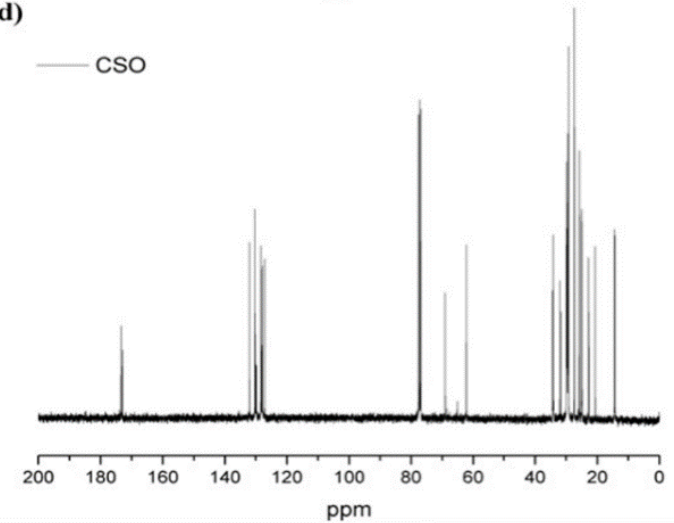

Figure $3 .{ }^{13} \mathrm{C}$ NMR spectra of CIP (a); CSP (c) with their respective CIO (b) and CSO (d). 


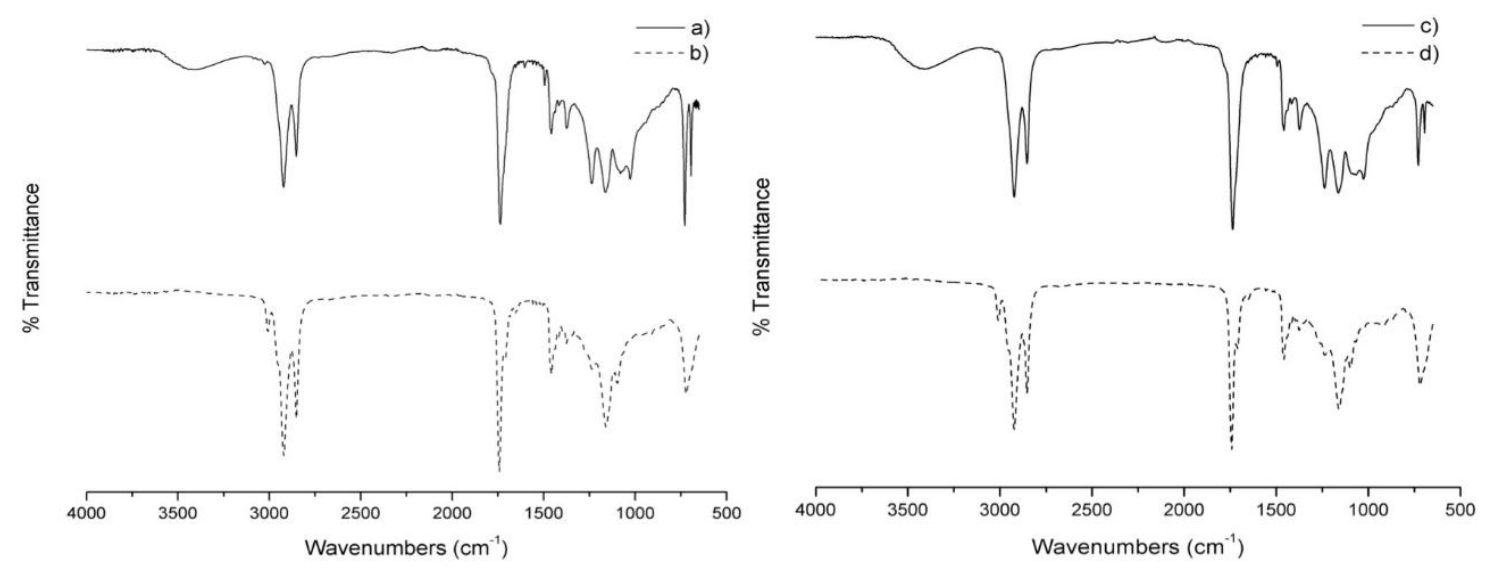

Figure 4. FTIR spectra of CIP (a); CSP (c) whit their respective CIO (b) and CSO (d).

\subsubsection{FTIR Analysis}

In order to complement the NMR analysis, the successful conversion of CIO and CSO into polyols was confirmed qualitatively by FTIR spectroscopy. These spectra are compared in Figure 3a-d, respectively. Figure 4a,c shows the FTIR spectra of CIP and CSP, respectively. Both polyols' FTIR spectra exhibited a broad peak centered approximately at $3400 \mathrm{~cm}^{-1}$, which were assigned to the presence of a hydroxyl $(-\mathrm{OH})$ stretching vibration. Another difference between CIP and CSP with their respective oils was the most intensive band $(\mathrm{C}=\mathrm{O}$, carbonyl stretching), attributed to the presence of the ester linkage. It slightly shifted from 1748.0 to $1738.8 \mathrm{~cm}^{-1}$ for CIO and CIP, respectively. The same behavior was found for CSO and the CSP, in this case. the band slightly shifted from 1743.7 to $1734.3 \mathrm{~cm}^{-1}$, respectively. Another important asymmetrical stretching band present in both FTIR spectra polyols corresponded to $\mathrm{C}-\mathrm{O}-\mathrm{C}$ groups at $1158 \mathrm{~cm}^{-1}$. It is important to mention that the absence of the bands at around 870 and $920 \mathrm{~cm}^{-1}$, assigned to the epoxy groups in both spectra polyols, corroborate that the hydroxylation reaction of the oils was complete. Finally, the bands at 2919.6 and $2846.1 \mathrm{~cm}^{-1}$, and 2924.3 and $2850 \mathrm{~cm}^{-1}$, assigned to asymmetrical and symmetrical stretching $\mathrm{CH}$ groups for CIP and CSP, respectively, were also detected. This evidence from FTIR analysis confirmed the formation of polyols, and the results obtained by ${ }^{1} \mathrm{H}$ and ${ }^{13} \mathrm{C}$ NMR.

\subsubsection{TGA Analysis}

In order to investigate the influence of the structure and composition on thermal stability of the oils and polyols, thermogravimetric analysis was performed in the interval from 30 to $600{ }^{\circ} \mathrm{C}$. The TG curves are shown in Figure 5, respectively. Following the same analysis used for NMR and FTIR discussion, we compare the thermograms obtained for polyols and their respective oils. Analyzing the curves in Figure 5, the weight loss curves for the thermal degradation of both polyols closely resembles the TG curves of their starting oils. It is important to note that CIO and CSO are more thermally stable than their respective polyols. This behavior is probably related to the binding energy of the unsaturated chains functionalized during hydroxylation reactions. Specifically, the $\mathrm{C}=\mathrm{C}$ and $\mathrm{CH}$ bonds present in the oils have binding energies of 614.2 and $413.4 \mathrm{~kJ} \cdot \mathrm{mol}^{-1}$, respectively, which enables them to be more thermally stable than the $\mathrm{CO}$ bond present in polyols, which has a lower binding energy $\left(353.5 \mathrm{~kJ} \cdot \mathrm{mol}^{-1}\right)[41]$.

According to the TG curves shown in Figure $4 \mathrm{a}$ and c, CIP and CSP exhibited slightly less thermal stability compared to their oils. In addition, the initial weight loss observed under $100{ }^{\circ} \mathrm{C}$ in the TG curve, in both polyols, could be attributed to the loss of the residual toluene molecules, which, as commented before, was used in the polyol synthesis. In the oils at $100{ }^{\circ} \mathrm{C}$, this weight loss was not observed. The total weight loss for both polyols was about $95 \%$, meanwhile, the oils degraded completely [42]. We suggest that these results could be due to the presence of hydroxyl groups in the polyol. 
The TG curve of CIP indicates another degradation stage (Figure 5a) at $400.24{ }^{\circ} \mathrm{C}$. The degradation mechanism probably corresponded to saturated and unsaturated fatty acid decomposition. On the other hand, a quite different decomposition was observed for the CSP; its major decomposition occurred in three steps starting at $196.00,305.10$, and $428.24{ }^{\circ} \mathrm{C}$, respectively. Specifically, the stage centered at $232.39{ }^{\circ} \mathrm{C}$ was caused presumably by the decomposition of the functionalized alpha-linolenic fatty acid chains. Furthermore, the main and biggest oil decomposition occurred between 305.10 and $428.24{ }^{\circ} \mathrm{C}$, which was attributed to monounsaturated and saturated fatty acid decomposition, respectively. Finally, the last one had a weight loss centered at $435.68^{\circ} \mathrm{C}$, corresponding to the secondary thermal decomposition superimposed on the main reaction.
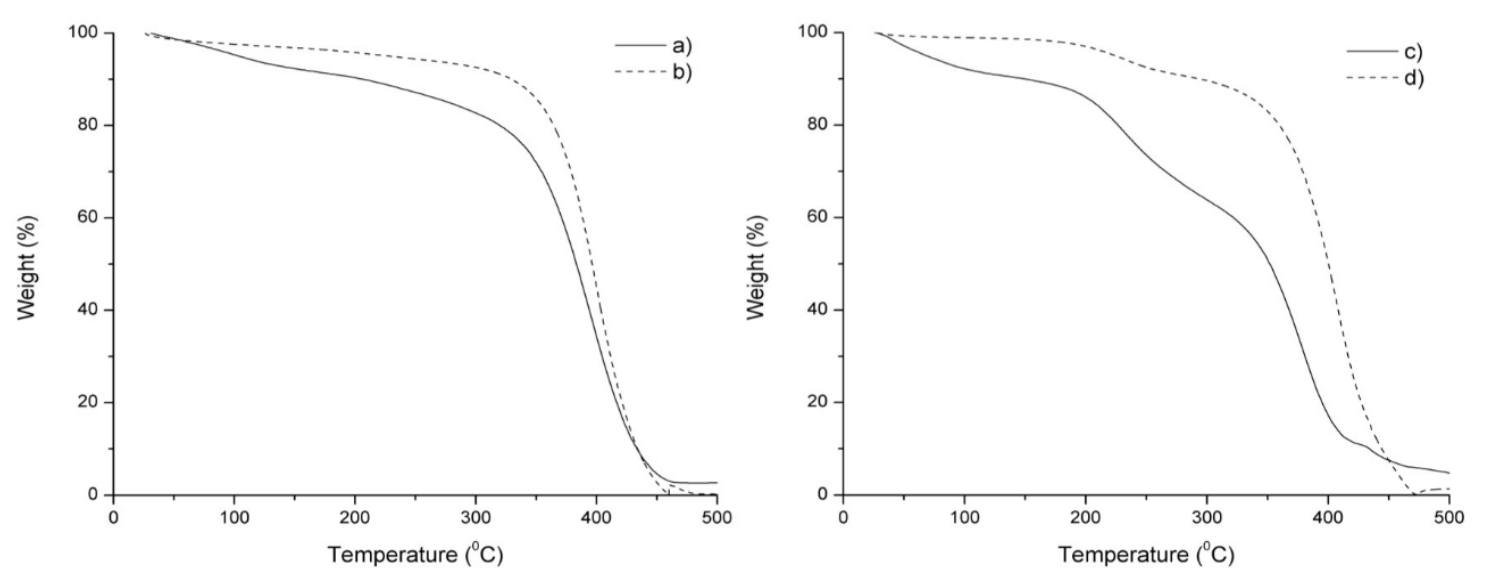

Figure 5. Thermogravimetric analysis (TGA) curve of CIP (a); CSP (c) with their respective CIO (b) and CSO (d).

Physicochemical Characteristics of Vegetable Polyols

Moreover, we determined the acid value (AV), iodine vale (IV), saponification number (SN), kinematic viscosity, density, and $\mathrm{OH}$ numbers of the polyols, and the results are also included in Table 2.

The AV and SN for the polyol samples were higher when compared to the starting oils. It is important to mention that the CIP and CSP samples did not contain free acids, other than fatty acids; then, the acid value may be directly converted to percent free fatty acids. Hence, the slight increase in the $\mathrm{AV}$ and $\mathrm{SN}$ could be associated with the possible deterioration of the studied oils at the moment of producing polyols, such as rancidity. Dileesh et al. reported that the cause for rancidity is the hydrolytic or oxidative cleavage of triglycerides, causing the formation of free fatty acids in oils or fats [43]. The same behavior occurred with the values of kinematic viscosity and density, and both values are major, as expected. In the case of the viscosity, the values for CIP and CSP were 3637 and $5746 \mathrm{~mm}^{2} / \mathrm{s}$, respectively. The big difference in these values were due to the hydrogen bonding, which was directly proportional to the major amount of $\mathrm{OH}$ groups present in the CSP (see $\mathrm{OH}$ functionality in Table 2). The obtained results showed a similarity tendency with the results reported by Knothe and Steidly [44]. In this study, the authors mentioned that free fatty acids or compounds with hydroxy groups possessed significantly higher viscosity than the starting material without hydroxy groups. Additional proof that the hydrolysis reaction of $\mathrm{CIO}$ and $\mathrm{CSO}$ had occurred was reflected in the iodine values of their respective polyols. While examining the iodine values for the CIP and CSP and their respective oils, the values decreased dramatically, which was evident since the unsaturation $(C=C$ bonds) in the CIO and CSO were replaced by hydroxyl groups.

Furthermore, we determined the $\mathrm{OH}$ functionality, which is an important indicator of the crosslinking that can be obtained in future polyurethane foams. The $\mathrm{OH}$ numbers of the $\mathrm{CIP}$ and CSP were 225.0 and $240.8 \mathrm{mg} \mathrm{KOH} / \mathrm{g}$, respectively. The theoretical molecular weight $\left(M_{w}\right)$ shown in Table 2 for CIP and CSP (1122.4 and $1166.1 \mathrm{~g} / \mathrm{mol}$, respectively) was calculated from the composition 
of polyols, based on assumption that no oligomers were formed, and considering that one $\mathrm{OH}$ group was formed per double bond. The $\mathrm{OH}$ functionality results showed values of 4.50 and $5.00 \mathrm{for} \mathrm{CIP}$ and CSP, respectively. It is important to note that these differences between the $\mathrm{OH}$ values were due to the fatty composition of the starting oils. According to these values, we can expect the preparation of rigid foams [45]. Rigid polyurethane foams are widely used in engineering applications, such as thermal insulation, building materials, chemical pipelines, and space filling, among others [46].

Finally, we compared the results of polyols with other commercial polyols using the parameters described before, specifically $\mathrm{OH}$ functionality, such as epoxidized soybean $\left(\mathrm{soy}-\mathrm{H}_{2}\right)$ [47], organosolv lignin, and soda lignin-based polyols with $\mathrm{OH}$ functionality values of 3.5, 6.0, and 9.0, respectively [48-50]. These results show that our product could be used as a potential economical and environmentally friendly material to obtain rigid foams.

\section{Conclusions}

Two novel polyols were successfully synthesized from two non-edible vegetable oils, C. integerrima and C. salicifolia, by in situ epoxidation and hydroxylation of oils in a one single step. The physicochemical and spectroscopic analysis, presented above, successfully characterized the reactions of polyol formation. Specifically, the FTIR, TGA, and NMR spectroscopic results confirmed complete disappearance of the signature of the double bonds present in the vegetable oils, and the incorporation of hydroxyl groups to form their respective polyols. In addition, the iodine value, acid value, hydroxyl number, hydroxyl functionality, density, and viscosity of the synthesized polyols were also successfully determined. All these values were higher for CIP and CSP when compared to starting oils, with the exception of the iodine value, which decreased to near 0 . Finally, the data collected in this study have established an essential starting point for the obtention of new materials. Specifically, we plan for a future study to examine the obtention of a new class of rigid polyurethane foams that could be used in engineering applications.

Author Contributions: D.A.-M. peformed the physico-chemical characterization of vegetable oils and synthetized the polyols; Y.M.-G., C.B. and J.C. obtained the oils and conceived/designed the experiments; O.V. and A.F.d.I.T. performed the characterization by FTIR, NMR and TGA; D.A.-M., O.V. and J.C. analyzed the data; D.A.-M., Y.M.-G. and O.V. wrote the paper.

Funding: This research was funded by Proyecto Fondecyt de Iniciación and Proyecto FIC-Regional grant numbers 11170008 and VIP30345879-0, respectively.

Acknowledgments: The Project was supported by the Proyecto Fondecyt de Iniciación (No. 11170008) and Proyecto FIC-Regional (No. VIP30345879-0). We thank Rachael Jiménez-Lange from the Academic Writing Center at the Programa de Idiomas of the Universidad de Talca.

Conflicts of Interest: The authors declare no conflicts of interest.

\section{References}

1. Eissen, M.; Metzger, J.O.; Schmidt, E.; Schneidewind, U. 10 Years after Rio-Concepts on the Contribution of Chemistry to a Sustainable Development. Angew. Chem. Int. Ed. 2002, 41, 414-436. [CrossRef]

2. Tian, H.; Tang, Z.; Chen, X.; Jing, X. Biodegradable synthetic polymers: Preparation, functionalization and biomedical application. Prog. Polym. Sci. 2012, 37, 237-280. [CrossRef]

3. Biermann, U.; Friedt, W.; Lang, S.; Luhs, W.; Machmuller, G.; Metzger, J.O.; Klaas, M.R.G.; Schafer, H.J.; Scheider, M.P. New syntheses whit oils and fast as renewable raw materials for the chemical industry. Angew. Chem. Int. Ed. 2000, 39, 2206-2224. [CrossRef]

4. SenihaGüner, F.; Yağcl, Y.; TuncerErciyes, A. Polymers from triglyceride oils. Prog. Polym. Sci. 2006, 31, 633-670. [CrossRef]

5. de Espinosa, L.M.; Meier, M.A.R. Plant oils: The perfect renewable resource for polymer science? Eur. Polym. J. 2011, 47, 837-852. [CrossRef]

6. Zhang, C.; Madbouly, S.A.; Kessler, M.R. Biobased polyurethanes prepared from different vegetable oils. ACS Appl. Mater. Interfaces 2015, 7, 1226-1233. [CrossRef] [PubMed] 
7. Chaudhari, A.; Kulkarni, R.; Mahulikar, P.; Sohn, D.; Gite, V. Development of PU coatings from neem oil based alkyds prepared by the monoglyceride route. J. Am. Oil Chem. Soc. 2015, 92, 733-741. [CrossRef]

8. Fernandes, F.C.; Kirwan, K.; Lehane, D.; Coles, S.R. Epoxy resin blends and composites from waste vegetable oil. Eur. Polym. J. 2017, 89, 449-460. [CrossRef]

9. Sinadinović-Fišer, S.; Janković, M.; Petrović, Z.S. Kinetics of in situ epoxidation of soybean oil in bulk catalyzed by ion exchange resin. J. Am. Oil Chem. Soc. 2001, 78, 725-731. [CrossRef]

10. Khoe, T.H.; Otey, F.H.; Frankel, E.N. Rigid urethane foams from hydroxymethylated linseed oil and polyol esters. J. Am. Oil Chem. Soc. 1972, 49, 615-618. [CrossRef]

11. Guo, A.; Demydov, D.; Zhang, W.; Petrovic, Z.S. Polyols and polyurethanes from hydroformylation of soybean oil. J. Polym. Environ. 2002, 10, 49-52. [CrossRef]

12. Petrović, Z.S.; Zhang, W.; Javni, I. Structure and properties of polyurethanes prepared from triglyceride polyols by ozonolysis. Biomacromolecules 2005, 6, 713-719. [CrossRef] [PubMed]

13. Caillol, S.; Desroches, M.; Carlotti, S.; Auvergne, R.; Boutevin, B. Synthesis of new polyurethanes from vegetable oil by thiol-ene coupling. Green Mater. 2012, 1, 16-26. [CrossRef]

14. Chuayjuljit, S.; Maungchareon, A.; Saravari, O. Preparation and properties of palm oil-based rigid polyurethane nanocomposite foams. J. Reinf. Plast. Compos. 2010, 29, 218-225. [CrossRef]

15. Hu, Y.H.; Gao, Y.; Wang, D.N.; Hu, C.P.; Zu, S.; Vanoverloop, L.; Randall, D. Rigid polyurethane foam prepared from a rape seed oil based polyol. J. Appl. Polym. Sci. 2002, 84, 591-597. [CrossRef]

16. Desroches, M.; Escouvois, M.; Auvergne, R.; Caillol, S.; Boutevin, B. From vegetable oils to polyurethanes: Synthetic routes to polyols and main industrial products. Polym. Rev. 2012, 52, 38-79. [CrossRef]

17. Kaushik, N.; Bhardwaj, D. Screening of Jatropha curcas germplasm for oil content and fatty acid composition. Biomass Bioenergy 2013, 58, 210-218. [CrossRef]

18. John, J.; Bhattacharya, M.; Turner, R.B. Characterization of polyurethane foams from soybean oil. J. Appl. Polym. Sci. 2002, 86, 3097-3107. [CrossRef]

19. Petrović, Z.S.; Javni, I.; Jing, X.; Hong, D.P.; Guo, A. Effect of hyperbranched vegetable oil polyols on properties of flexible polyurethane foams. Mater. Sci. Forum 2007, 555, 459-465.

20. Prociak, A.; Rojek, P.; Pawlik, H. Flexible polyurethane foams modified with natural oil based polyols. J. Cell. Plast. 2012, 48, 489-499. [CrossRef]

21. Singh, A.P.; Bhattacharya, M. Viscoelastic changes and cell opening of reacting polyurethane foams from soy oil. Polym. Eng. Sci. 2004, 44, 1977-1987. [CrossRef]

22. Liigadas, G.; Ronda, J.C.; Galià, M.; Cádiz, V. Plant as Platform chemical for polyurethane synthesis: Current-State-of-the-Art. Biomacromolecules 2010, 11, 2825-2835. [CrossRef] [PubMed]

23. Piloto-Rodríguez, R.; Melo, E.A.; Goyos-Pérez, L.; Verhelst, S. Conversion of by-products from the vegetable oil industry into biodiesel and it is use in internal combustion engines: A review. Braz. J. Chem. Eng. 2014, 31, 287-301. [CrossRef]

24. Bittner, M.; Alarcón, J.; Aqueveque, P.; Becerra, J.; Hernández, V.; Hoeneisen, M.; Silva, M. EstudioQuímico De Especies de la Familia EuphorbiaceaeEn Chile. Bol. Soc. Chil. Quím. 2001, 46, 419-431. [CrossRef]

25. Galarce, G.; Trivelli, M. Reseñasobre la flora y vegetación de la serranía El Asiento, San Felipe, Región de Valparaíso. ServicioAgrícolaGanadero 2013, 1-118. Available online: https:/ /www.sag.gob.cl/sites/default/ files/flora_san_felipe_2013.pdf (accessed on 14 August 2018).

26. Bull-Hereñu, K.; Martínez, E.A.; Squeo, F.A. Structure and genetic diversity in colliguajaodorifera Mol. (Euphorbiaceae), a shrub subjected to pleisto-holocenic natural perturbations in a Mediterranean South American Region. J. Biogeogr. 2005, 32, 1129-1138. [CrossRef]

27. Pinto, G.; Toledo, I.; Córdoba, L.; Flores, M.; Cabrera, J. Análisisfitoquímico de C. integerrima (Hook.) Gill. Et Hook. (Euphorbiaceae), una planta de la Patagonia Argentina. Acta FarmacéuticaBonaerense 2004, 23, 459-465.

28. Alvarez, M.E.; Gil, R.; Acosta, M.G.; Saad, R.J.; Borkowski, E.; María, A.O.M. Diuretic activity of aqueous extract and betulin from C. integerrima in rats. Pharm. Biol. 2009, 47, 274-278. [CrossRef]

29. AOAC. Official Method Cd 3d-63, Am2-93, Official Methods and Recommended Practices of the American Oil Chemists' Society; AOCS Press: Champaign, IL, USA, 1995.

30. Monteavaro, L.; da Silva, E.; Costa, A.; Samios, D.; Gervase, A.; Petzhold, C. Polyurethane networks from formiated soy polyols: Synthesis and mechanical characterization. J. Am. Oil Chem. Soc. 2005, 82, 365-371. [CrossRef] 
31. Morrison, W.R.; Smith, L.M. Preparation of fatty acid methyl esters and dimethylacetals from lipids with boron fluoride-methanol. J. Lipid. Res. 1964, 5, 600-608. [PubMed]

32. Fatemi, S.H.; Hammond, E.G. Analysis of oleate, linoleate and linolenate hydroperoxides in oxidized ester mixtures. Lipids 1980, 15, 379-385. [CrossRef]

33. AOAC. Official Method Cd 3d-63, Official Methods and Recommended Practices of the American Oil Chemists' Society; AOCS Press: Champaign, IL, USA, 1993.

34. AOAC-Association of Official Analytical Chemists. Official Methods of Analysis, 18th ed.; Association of Official Analytical: Washington, DC, USA, 2005.

35. Zlatanić, A.; Lava, C.; Zhnag, W.; Petrović, Z.S. Effect of structure on properties of polyols and polyurethanes based on different vegetable oils. J. Polym. Sci. B 2004, 42, 809-819. [CrossRef]

36. American Society for Testing Materials. Polyurethane Raw Materials: Determination of Hydroxyl Numbers of Polyols; ASTM (D 4274-05); ASTM: West Conshohocken, PA, USA, 2005; pp. 1-9.

37. Gunstone, F.D.; John, L.H.; Fred, B.P. The Lipid Handbook; Chapman \& Hall Chemical Database: Washington, DC, USA, 1994.

38. Krisnangkura, K.; Yimsuwan, T.; Pairintra, R. An empirical approach in predicting biodiesel viscosity at various temperatures. Fuel 2006, 85, 107-113. [CrossRef]

39. Rodrigues, J.A., Jr.; Cardoso, F.P.; Lachter, E.R.; Estevao, L.R.M.; Lima, E.; Nascimento, R.S.V. Correlating chemical structure and physical properties of vegetable oil esters. J. Am. Oil Chem. Soc. 2006, 30, 353-357. [CrossRef]

40. Demirbas, A. Relationships derived from physical properties of vegetable oil and biodiesel fuels. Fuel 2008, 87, 1743-1748. [CrossRef]

41. Vollhardt, K.P.C.; Schore, N.E. QuímicaOrgánica: Estructura y Función, 5th ed.; OMEGA D.L.: Barcelona, Spain, 2007.

42. Javni, I.; Petrovic, Z.S.; Guo, A.; Fuller, R. Thermal stability of polyurethanes based on vegetable oils. J. Appl. Polym. Sci. 2000, 77, 1723-1734. [CrossRef]

43. Dileesh, S.; Adithya, M.; Sankar, A.; Peter, C.V. Determination of saponification, acid and ester values; percentage of free fatty acids and glycerol in some selected edible oils: Calculation of concentration of lye needed to prepare soap from these oils. Res. Sch. ISSN 2013, 2249-6696.

44. Knothe, G.; Steidly, K.R. Kinematic viscosity of biodiesel fuel components and related compounds. Influence of compound structure and comparison to petrodiesel fuel components. Fuel 2005, 84, 1059-1065. [CrossRef]

45. Tersac, G. Chemistry and Technology of Polyols for Polyurethanes; Ionescu, M., Ed.; Rapra Technology: Shrewsbury, UK, 2007; Chapter 12; pp. 317-319.

46. Narine, S.S.; Kong, X.; Bouzidi, L.; Sporns, P. Physical properties of polyurethanes produced from polyols from seed oils: II. Foams. J. Am. Oil Chem. Soc. 2007, 84, 65-72. [CrossRef]

47. Guo, A.; Cho, Y.; Petrovic, Z.S. Structure and properties of halogenated and nonhalogenated soy-based polyols. J. Polym. Sci. Part A Polym. Chem. 2000, 38, 3900-3910. [CrossRef]

48. Webster, D.C.; Pan, X. New biobased high functionality polyols and their use in polyurethane coatings. ChemSusChem 2012, 5, 419-429.

49. Nadji, H.; Bruzzèse, C.; Belgacem, M.N.; Benaboura, A.; Gandini, A. Oxypropylation of lignins and preparation of rigid polyurethane foams from the ensuing polyols. Macromol. Mater. Eng. 2005, 290, 1009-1016. [CrossRef]

50. Gandini, A.; Belgacem, M.N. Partial or total oxypropylation of natural polymers and the use of the ensuing materials as composites or polyol macromonomers. In Monomers, Polymers and Composites from Renewable Resources, 1st ed.; Belgacem, M.N., Gandini, A., Eds.; Elsevier: Oxford, UK, 2008.

(C) 2018 by the authors. Licensee MDPI, Basel, Switzerland. This article is an open access article distributed under the terms and conditions of the Creative Commons Attribution (CC BY) license (http:/ / creativecommons.org/licenses/by/4.0/). 